\title{
Placenta and Umbilical Cord Cause in Antepartum Deaths
}

Xenofon Mantakas ${ }^{1}$, Ioannis Dalivigkas ${ }^{2}$, Leon Aravantinos ${ }^{3}$, Nikos Goutas ${ }^{4}$, Christina Goudeli ${ }^{5}$, Nikos Vlahos $^{3}$

1. Pathology, Aretaieio Hospital, Athens, GRC 2. Obstetrics and Gynecology, Attikon Hospital, Athens, GRC 3. Obstetrics and Gynecology, Aretaieio Hospital, Athens, GRC 4. Pathology, Medical School of Athens, Athens, GRC 5. Obstetrics and Gynecology, “Saint Savvas” Cancer Hospital, Athens, GRC

Corresponding author: Xenofon Mantakas, xenmantakas@gmail.com

\begin{abstract}
Stillbirth is a sudden and painful event for parents and obstetrical specialists as well. It is, therefore, of greatest importance to be able to give answers for the cause in order to plan a subsequent pregnancy. The aim of this retrospective study is to estimate the placental and umbilical cord cause of intrauterine death in relation to different gestational ages. The study took place on the Medical Birth Registry of Aretaieio Hospital, National and Kapodistrian University, Athens, Greece. We include a total of 19,283 pregnancies from 1998 to 2012. In this study period, 431 embryonic deaths occurred. The clinical history was documented on admission at delivery. Conditions thought to be associated with the intrauterine fetal death were recorded. Gestational age was calculated from the last menstrual period as well as with the threetrimester system. The autopsy, placenta and umbilical cord examination were performed by the same laboratory of pathology in Aretaieio University Hospital. We found that the majority of stillbirths occurred in the second trimester. We examined placenta and umbilical cord in all cases. The most frequent histologic abnormalities were those indicated placental vascular insufficiency. As far as the umbilical cord is concerned we found that the inflammatory disorder was the most common in antepartum deaths. A single umbilical artery was significantly related to gestational diabetes and congenital embryonic anomalies. Finally, our results showed steady declines in antepartum deaths during 1998-2012. As a result, we reached the conclusion that in order to reduce the fetal death rate, we have to insist on the autopsy of the placenta and umbilical cord in order to gain the appropriate information in counseling the parents.
\end{abstract}

Categories: Obstetrics/Gynecology, Pathology

Keywords: stillbirth, antepartum death, placenta, umbilical cord, second trimester

\section{Introduction}

The intrauterine fetal or antepartum death of second and third trimester, especially in pregnancies without any risk factor, is often unexpected and unexplained [1-3]. As per the definition by World Health

Organization (WHO), stillbirth or fetal death is death prior to the complete expulsion or extraction from its mother of a product of conception, irrespective of the duration of pregnancy; the death is indicated by the fact that after such separation the fetus does not breathe or show any other sign of life, such as beating of the heart, pulsation of the umbilical cord or definite movement of voluntary muscles [4]. In developed countries, where interventions have largely eliminated excess early neonatal mortality, over six out of 10 perinatal deaths are stillbirths [5]. There are many references to unexpected fetal deaths related to placental dysfunction or to umbilical cord cause [6-8]. Placental bed pathology involves inadequate spiral artery pathology or both leading to maternal vascular under perfusion [6, 9, 10]. It involves as well abnormalities in the parenchyma that are reflected in the weight of the placenta, placental hypoplasia and many other dysfunctions like placental infection and abnormal development of placenta villous $[6,10,11]$. There are currently at least 32 classification systems of stillbirth, many of which have been developed for different purposes $[12,13]$. They have different categories of classifying causes. In the new ones TULIP-Relevant Condition at Death (RECODE-UK) placenta and umbilical cord pathology consist the most common cause of fetal death [9]. Many other classification systems have no mention on the placenta and therefore the largest group of fetal death remains nonspecific $[6,7,14]$. Antepartum death can be divided by gestational age into early (20-28 weeks) or late deaths (more than 28 weeks) or into the second and third trimester. At the same time, a conventional autopsy is considered the diagnostic gold standard, because it can confirm or augment antemortem findings, fulfill the need for placental information, assist with future planning as well as provide answers about what had happened $[3,15,16]$. The aim of this retrospective study is to estimate the placental cause of intrauterine death in relation to different gestational ages. It is important to note that no other study with this time duration, parameters, and a large population has ever been released in Greece [17, $18]$.

\section{Materials And Methods}

The purpose was to study the dysfunctions of the placenta and umbilical cord in all antepartum deaths after the second trimester in Aretaieio University Hospital of Athens from 1998 to 2012. The study was a 
population-based registry study. We excluded stillbirths less than second trimester (20 weeks) of gestation and therapeutic abortions-terminated pregnancies. Any additional births that lacked information on the placenta and umbilical cord autopsy were also excluded. As a result, we included 19,283 births. Gestational age was calculated from the last menstrual period as well as with the three-trimester system. In few cases of 1990s that the gestational age was not provided, we used the Crown-Rump Length (CRL) to calculate the gestational week. It is however unlikely that change in the estimation of gestational length has significantly biased our results because gestational age was defined mainly as three trimesters. Among the cases, we included 49 multiple/twin pregnancies (47 twins and two triplets) of at least one death of the embryo. The clinical history was documented on admission at delivery. Conditions thought to be associated with the intrauterine fetal death were recorded. The autopsy and placenta and umbilical cord examination were performed by the same laboratory in Aretaieio University Hospital. Quantitative variables were expressed as mean values (SD), while qualitative variables were expressed as absolute and relative frequencies. For the comparisons of proportions, chi-square and Fisher's exact tests were computed. Analysis of variance (ANOVA) was used for the comparison of mean values. Rates of embryonic death per 1000 ongoing pregnancies were calculated in the total sample and by year of delivery. Relative risks of embryonic death and their 95\% confidence intervals were calculated for each time period, with 1998-2002 as the reference period. Statistical significance was set at $\mathrm{p}<0.05$ and analyses were conducted using SPSS statistical software version 22.0 (IBM Corp., Armonk, NY).

\section{Results}

A total of 19,283 pregnancies in Aretaieio University Hospital of Athens from 1998 to 2012 were included in the study. In the study period, 431 embryonic deaths $(23.9 \%)$ occurred. Characteristics of the embryonic deaths, pregnancies and mother's demographics are presented in Table 1. 


\section{Cureus}

\begin{tabular}{|c|c|}
\hline & N (\%) \\
\hline Mother's age, mean (SD) & $31.7(5.3)$ \\
\hline \multicolumn{2}{|l|}{ Gender } \\
\hline Males & $239(51.8)$ \\
\hline Females & $222(48.2)$ \\
\hline Gestational week, mean (SD) & $21.8(6.2)$ \\
\hline \multicolumn{2}{|l|}{ Gestational week } \\
\hline$<20$ th & $177(38.4)$ \\
\hline 20th-27th & $212(46.0)$ \\
\hline$>27$ th & $72(15.6)$ \\
\hline \multicolumn{2}{|l|}{ Trimester } \\
\hline 2nd & 376 (81.6) \\
\hline $3 r d$ & $85(18.4)$ \\
\hline Mixed & $124(26.9)$ \\
\hline Nonspecific cause & $13(2.8)$ \\
\hline Congenital embryonic anomalies & $14(3.0)$ \\
\hline \multicolumn{2}{|l|}{ If yes, define } \\
\hline Polycystic kidney dysplasia & $4(0.9)$ \\
\hline Congenital heart disease & $6(1.3)$ \\
\hline Tail tracheal aggression syndrome & $1(0.2)$ \\
\hline Fallot tetralogy & $3(0.7)$ \\
\hline Embryonic vascular disorders & $7(1.5)$ \\
\hline \multicolumn{2}{|l|}{ If yes, define } \\
\hline Embryonic vascular thrombopathy & $1(0.2)$ \\
\hline Intrauterine transfusion syndrome & $6(1.3)$ \\
\hline Pregnancy diseases & $18(3.9)$ \\
\hline \multicolumn{2}{|l|}{ If yes, define } \\
\hline Cytomegalovirus (CMV) & $1(0.2)$ \\
\hline Diabetes & $16(3.5)$ \\
\hline Toxoplasma & $1(0.2)$ \\
\hline In vitro fertilization (IVF) & $38(8.2)$ \\
\hline
\end{tabular}

TABLE 1: Embryonic deaths, maternal and pregnancies characteristics.

The majority of the embryonic deaths occurred between 20th and 27th week of gestation (46.0\%). The mean age of the mother was 31.7 years $(\mathrm{SD}=5.3)$. Among the deaths, 239 were males $(51.8 \%)$. Most losses occurred in the second trimester (81.6\%). Congenital embryonic anomalies were present in $3 \%$ of the cases and embryonic vascular disorders in $1.5 \%$ of the cases. Diabetes was recorded in $3.5 \%$ of the pregnancies. In 38 cases $(8.2 \%)$ in vitro fertilization (IVF) was performed as it can be seen in Table 1 . Table 2 shows the results of placenta examination associated with embryonic deaths. The mean placental weight was $214.7 \mathrm{gr}(\mathrm{SD}=$ 119.8 ) and the mean placenta diameter was $13.1 \mathrm{~cm}(\mathrm{SD}=4.0)$. Vascular disorders were recorded in $38.6 \%$ of the samples and inflammatory disorders in $35.6 \%$ of the samples. Functional-structural disorders were present in $28.0 \%$ of the placentas and abruption in $13.7 \%$ of them. 


\section{Cureus}

\begin{tabular}{|c|c|}
\hline & $\mathbf{N}(\%)$ \\
\hline Placenta weight (gr), mean (SD) & 214.7 (119.8) \\
\hline Placenta diameter (cm), mean (SD) & $13.1(4.0)$ \\
\hline Vascular disorders & $178(38.6)$ \\
\hline \multicolumn{2}{|l|}{ If yes, define } \\
\hline Occlusion & 75 (16.3) \\
\hline Occlusion-intravillus haematomas & $46(10.0)$ \\
\hline Occlusion-intervillous haematomas-thrombi & $57(12.4)$ \\
\hline Inflammatory disorders & $164(35.6)$ \\
\hline \multicolumn{2}{|l|}{ If yes, define } \\
\hline Infection of villus and necrosis after certain infection & $2(0.4)$ \\
\hline Infection of villus & $8(1.7)$ \\
\hline Acute-in part necrotic chorioamnionitis & 57 (12.4) \\
\hline Acute chorioamnionitis & $93(20.2)$ \\
\hline Acute chorioamnionitis and infection of placenta & $2(0.4)$ \\
\hline Functional-structural disorders & $129(28.0)$ \\
\hline \multicolumn{2}{|l|}{ If yes, define } \\
\hline Villi immaturity & $52(11.3)$ \\
\hline Fibrin deposition & 54 (11.7) \\
\hline Necrosis & $3(0.7)$ \\
\hline Villi necrosis & $5(1.1)$ \\
\hline Intrauterine transfusion syndrome & $1(0.2)$ \\
\hline Hydrophilic & $13(2.8)$ \\
\hline Placenta abruption & $63(13.7)$ \\
\hline \multicolumn{2}{|l|}{ If yes, define } \\
\hline Backplate haematomas & $63(13.7)$ \\
\hline
\end{tabular}

TABLE 2: Results from placenta examination associated with embryonic deaths.

As it can be seen in Figure 1 the most common placenta of multiple pregnancies of at least one stillbirth was a monocular one. 


\section{Cureus}

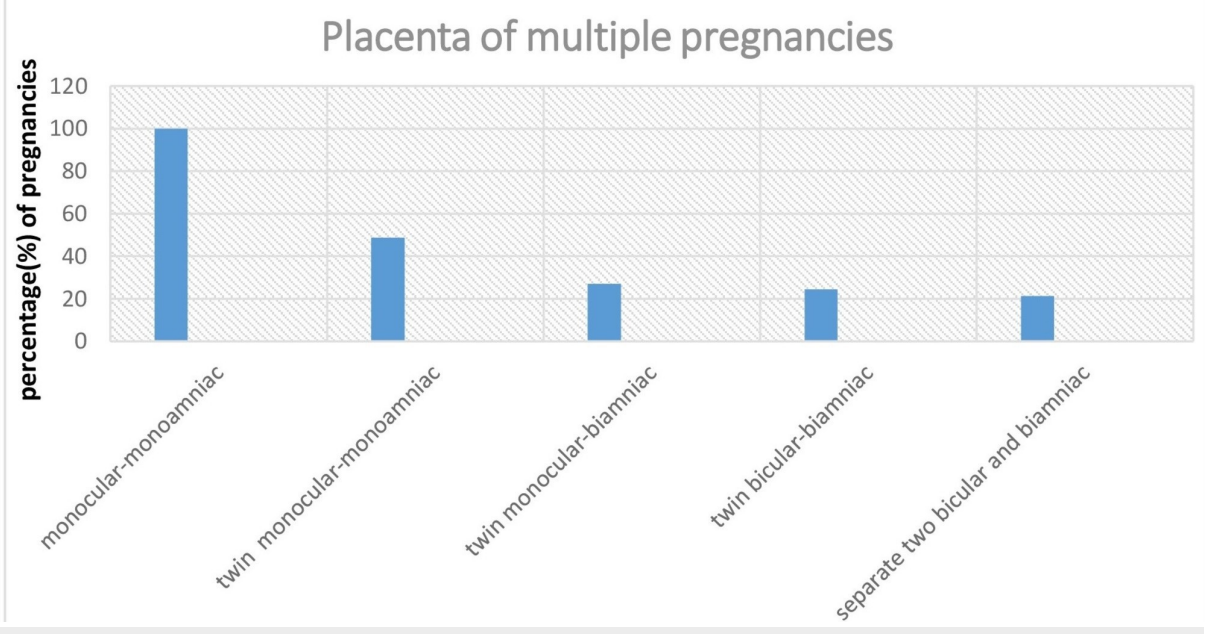

FIGURE 1: Placenta and multiple pregnancies of at least one stillbirth.

Results from placenta and umbilical cord examination according to the time period and gestational week are presented in Table 3. 


\begin{tabular}{|c|c|c|c|c|c|c|c|c|}
\hline & \multicolumn{3}{|l|}{ Year } & \multirow{3}{*}{$\mathbf{P}$} & \multicolumn{3}{|c|}{ Gestational week } & \multirow{3}{*}{$\mathbf{P}$} \\
\hline & 1998-2002 & 2003-2007 & 2008-2012 & & $<20$ th & 20th-27th & $>27$ th & \\
\hline & $\mathrm{N}(\%)$ & $\mathrm{N}(\%)$ & $\mathrm{N}(\%)$ & & N (\%) & $\mathrm{N}(\%)$ & N (\%) & \\
\hline \multicolumn{9}{|l|}{ Placenta } \\
\hline Vascular disorders & $66(36.9)$ & $53(39.6)$ & $59(39.9)$ & $0.828^{+}$ & $59(33.3)$ & $91(42.9)$ & $28(38.9)$ & $0.154^{+}$ \\
\hline Inflammatory disorders & $58(32.4)$ & $56(41.8)$ & $50(33.8)$ & $0.197^{+}$ & $73(41.2)$ & $73(34.4)$ & $18(25.0)$ & $0.047^{+}$ \\
\hline $\begin{array}{l}\text { Functional-structural } \\
\text { disorders }\end{array}$ & $45(25.1)$ & $36(26.9)$ & $48(32.4)$ & $0.324^{+}$ & $56(31.6)$ & $53(25.0)$ & $20(27.8)$ & $0.348^{+}$ \\
\hline Placenta abruption & $22(12.3)$ & $22(16.4)$ & $19(12.8)$ & $0.540^{+}$ & $25(14.1)$ & 31 (14.6) & $7(9.6)$ & $0.564^{+}$ \\
\hline Weight (gr), mean (SD) & $\begin{array}{l}214.9 \\
(113.1)\end{array}$ & $\begin{array}{l}211.4 \\
(131.8)\end{array}$ & $\begin{array}{l}21 / .4 \\
(117.1)\end{array}$ & $0.918^{\mp}$ & $\begin{array}{l}127.9 \\
(61.4)\end{array}$ & $\begin{array}{l}221.2 \\
(56.8)\end{array}$ & $\begin{array}{l}406.8 \\
(134.2)\end{array}$ & $<0.001^{\ddagger}$ \\
\hline Diameter (cm), mean (SD) & $13.8(4.6)$ & $13(3.6)$ & $12.4(3.5)$ & $0.005^{\ddagger}$ & $10.1(2.9)$ & $13.9(2.4)$ & $18.3(3.9)$ & $<0.001^{\ddagger}$ \\
\hline \multicolumn{9}{|l|}{ Umbilical cord } \\
\hline Vascular disorders & $10(5.6)$ & $8(6.0)$ & $11(7.4)$ & $0.781^{+}$ & $7(4.0)$ & $14(6.6)$ & $8(11.1)$ & $0.107^{+}$ \\
\hline Inflammatory disorders & $27(15.1)$ & $18(13.5)$ & $19(12.8)$ & $0.834^{+}$ & $27(15.3)$ & $29(13.7)$ & $8(11.1)$ & $0.677^{+}$ \\
\hline Tourniquet & $7(3.9)$ & $9(6.8)$ & $6(4.1)$ & $0.445^{+}$ & $2(1.1)$ & $5(2.4)$ & $15(20.8)$ & $<0.001^{+}$ \\
\hline Single umbilical artery & $9(5.0)$ & $8(6.0)$ & $8(5.4)$ & $0.930^{+}$ & $12(6.8)$ & $11(5.2)$ & $2(2.8)$ & $0.434^{+}$ \\
\hline \multicolumn{9}{|l|}{ Umbilical cord adhesion } \\
\hline Eccentric & $156(87.2)$ & $111(83.5)$ & $120(81.1)$ & $0.495^{+}$ & $156(88.6)$ & $173(81.6)$ & $58(80.6)$ & $0.291^{+}$ \\
\hline Low & $16(8.9)$ & $17(12.8)$ & $23(15.5)$ & & $14(8.0)$ & $31(14.6)$ & $11(15.3)$ & \\
\hline Hymenus & $7(3.9)$ & $5(3.8)$ & $5(3.4)$ & & $6(3.4)$ & $8(3.8)$ & $3(4.2)$ & \\
\hline Length, mean (SD) & $22(10.7)$ & $23.8(21.1)$ & $17.3(10.5)$ & $<0.001^{\ddagger}$ & $16.1(17.3)$ & $21(7.8)$ & 33.2 (16.2) & $<0.001^{\ddagger}$ \\
\hline Diameter, mean (SD) & $0.91(0.30)$ & $0.81(0.30)$ & $0.77(0.30)$ & $<0.001^{\ddagger}$ & $0.68(0.30)$ & $0.87(0.30)$ & $1.15(0.30)$ & $<0.001^{\ddagger}$ \\
\hline Mixed & $47(26.3)$ & $37(27.6)$ & $40(27.0)$ & $0.964^{+}$ & $36(20.3)$ & $68(32.1)$ & $20(27.8)$ & $0.034^{+}$ \\
\hline Nonspecific cause & $6(3.4)$ & $3(2.2)$ & $4(2.7)$ & $0.938^{++}$ & $4(2.3)$ & $6(2.8)$ & $3(4.2)$ & $0.644^{++}$ \\
\hline $\begin{array}{l}\text { Congenital embryonic } \\
\text { anomalies }\end{array}$ & $7(3.9)$ & $6(4.5)$ & $1(0.7)$ & $0.099^{++}$ & $5(2.8)$ & $7(3.3)$ & $2(2.8)$ & $0.954^{+}$ \\
\hline Embryonic vascular disorders & $0(0.0)$ & $3(2.2)$ & $4(2.7)$ & $0.057^{++}$ & $0(0.0)$ & $5(2.4)$ & $2(2.8)$ & $0.065^{++}$ \\
\hline Pregnancy diseases & $8(4.5)$ & $6(4.5)$ & $4(2.7)$ & $0.657^{+}$ & $2(1.1)$ & $11(5.2)$ & $5(6.9)$ & $0.042^{+}$ \\
\hline in vitro rertilzation (IVF) & $6(3.4)$ & $10(7.5)$ & $22(14.9)$ & $0.001^{+}$ & $14(7.9)$ & $20(9.4)$ & $4(5.6)$ & $0.574^{+}$ \\
\hline
\end{tabular}

TABLE 3: Results from placenta and umbilical cord examination according to time period and gestational week.

${ }^{+}$Pearson's chi-square test; ${ }^{++}$Fisher's exact test; ${ }^{\ddagger}$ ANOVA

Inflammatory disorders of the placenta decreased significantly as the gestational week increases. As expected, both the weight and diameter of the placenta increased along with the increase of gestational week and the same result was found for the length and diameter of the umbilical cord. The diameter of the placenta and proportion of IVF also increased by the three time periods. Tourniquet was more frequent in greater gestational weeks. Also, the proportion of mixed and pregnancy diseases was lower in cases with 


\section{Cureus}

gestational weeks fewer than 20 . Table 4 shows results from umbilical cord examination.

\begin{tabular}{|l|l|}
\hline & N (\%) \\
\hline Umbilical cord length (cm), mean (SD) & $21.0(14.7)$ \\
\hline Umbilical cord diameter (cm), mean (SD) & $0.84(0.32)$ \\
Vascular disorders & $29(6.3)$ \\
\hline If yes, define & $29(6.3)$ \\
\hline Thrombosis & \\
\hline Inflammatory disorders & $64(13.9)$ \\
\hline If yes, define & $1(0.2)$ \\
\hline Degeneration-necrosis & $21(4.6)$ \\
\hline Umbilical cord infection & $42(9.1)$ \\
\hline Acute vasculitis & $22(4.8)$ \\
\hline Tourniquet & $25(5.4)$ \\
\hline Single umbilical artery & \\
\hline Umbilical cord adhesion & $17(3.7)$ \\
\hline Eccentric & $387(84.1)$ \\
\hline Low & $56(12.2)$ \\
\hline Hymenus & \\
\hline
\end{tabular}

TABLE 4: Results from umbilical cord examination associated with embryonic deaths.

The mean umbilical cord length was $21 \mathrm{~cm}(\mathrm{SD}=14.7)$ and the mean umbilical cord diameter was $0.84 \mathrm{~cm}$ $(\mathrm{SD}=0.32)$. Vascular disorders were recorded in $6.3 \%$ of the umbilical cord samples and inflammatory disorders in $13.9 \%$. Tourniquet was found in $4.8 \%$ of the umbilical cords. The single umbilical artery was recorded in 5.4\% of the samples. As it can be seen in Table 5, increased rates of gestational diabetes were found in cases where the single umbilical artery was found $(28 \%$ vs. $2.1 \%, \mathrm{p}<0.001)$. 


\section{Cureus}

\begin{tabular}{|c|c|c|c|c|c|c|}
\hline & & \multicolumn{4}{|c|}{ Single Umbilical Artery } & \multirow[b]{3}{*}{$\mathbf{P}$} \\
\hline & & \multicolumn{2}{|l|}{ NO } & \multicolumn{2}{|c|}{ YES } & \\
\hline & & $\mathrm{N}$ & $\%$ & $\mathrm{~N}$ & $\%$ & \\
\hline \multirow{2}{*}{ Pregnancy diabetes } & no & 426 & 97.9 & 18 & 72.0 & $<0.001 \|$ \\
\hline & yes & 9 & 2.1 & 7 & 28.0 & \\
\hline \multirow{3}{*}{ Umbilical cord adhesion } & eccentric & 369 & 84.8 & 18 & 72.0 & $<0.001 \|$ \\
\hline & low & 56 & 12.9 & 0 & 0.0 & \\
\hline & hymenus & 10 & 2.3 & 7 & 28.0 & \\
\hline Placenta weight (gr), mean (SD) & & \multicolumn{2}{|c|}{$216.4(121.1)$} & \multicolumn{2}{|c|}{$184.0(91.3)$} & $0.198 \rrbracket$ \\
\hline \multirow{2}{*}{ Congenital embryonic abnormalities } & no & 429 & 98.6 & 17 & 68.0 & $<0.001 \|$ \\
\hline & yes & 6 & 1.4 & 8 & 32.0 & \\
\hline
\end{tabular}

\section{TABLE 5: Results from cases with single umbilical artery.}

" Fisher's exact test; " " Student's t-test

Also, congenital embryonic anomalies were more frequent in cases where the single umbilical artery was found ( $32 \%$ vs. $1.4 \%, \mathrm{p}<0.001$ ). Presence of vasculitis was more frequent in cases with thrombosis in umbilical cord $(34.5 \%$ vs. $7.4 \%, \mathrm{p}<0.001)$ or chorioamnionitis $(15.8 \%$ vs. $5.8 \%, \mathrm{p}<0.001)$, as it can be seen in Tables 6,7.

\begin{tabular}{|c|c|c|c|c|c|c|}
\hline & & \multicolumn{4}{|c|}{ Thrombosis } & \multirow{3}{*}{$\mathbf{P}$} \\
\hline & & \multicolumn{2}{|l|}{ NO } & \multicolumn{2}{|c|}{ YES } & \\
\hline & & $\mathrm{N}$ & $\%$ & $\mathrm{~N}$ & $\%$ & \\
\hline \multirow{2}{*}{ Vasculitis } & NO & 399 & 92.6 & 19 & 65.5 & $<0.001 \mid$ \\
\hline & YES & 32 & 7.4 & 10 & 34.5 & \\
\hline \multicolumn{2}{|c|}{ Length of the umbilical cord, mean (SD) } & \multicolumn{2}{|c|}{$20.7(14.7)$} & \multicolumn{2}{|c|}{$25.2(14.3)$} & $0.114 \pi$ \\
\hline
\end{tabular}

TABLE 6: Results from cases with thrombosis.

II Fisher's exact test; ${ }^{\text {Il }}$ Student's t-test

\begin{tabular}{|c|c|c|c|c|c|c|}
\hline & & \multicolumn{4}{|c|}{ Chorioamnionitis } & \multirow{3}{*}{ P Pearson's $x^{2}$ test } \\
\hline & & \multicolumn{2}{|l|}{ NO } & \multicolumn{2}{|l|}{ YES } & \\
\hline & & $\mathrm{N}$ & $\%$ & $\mathrm{~N}$ & $\%$ & \\
\hline \multirow{2}{*}{ Vasculitis } & no & 290 & 94.2 & 128 & 84.2 & $<0.001$ \\
\hline & yes & 18 & 5.8 & 24 & 15.8 & \\
\hline
\end{tabular}

TABLE 7: Results from cases with chorioamnionitis.

The length of umbilical cord was significantly greater in cases with wrapping or with placenta abruption ( $\mathrm{p}<$ $0.001)$, while the mean placental weight was greater in cases with gestational diabetes $(p=0.026)$, as it can 


\section{Cureus}

be seen in Tables $8-10$.

\begin{tabular}{|c|c|c|c|c|}
\hline & & \multicolumn{2}{|c|}{ Single umbilical cord } & \multirow{2}{*}{ P Student's t-test } \\
\hline & & Mean & SD & \\
\hline \multirow{2}{*}{ Wrapping } & No & 19.6 & 13.0 & $<0.001$ \\
\hline & Yes & 49.0 & 18.3 & \\
\hline
\end{tabular}

TABLE 8: Results from cases with single umbilical cord.

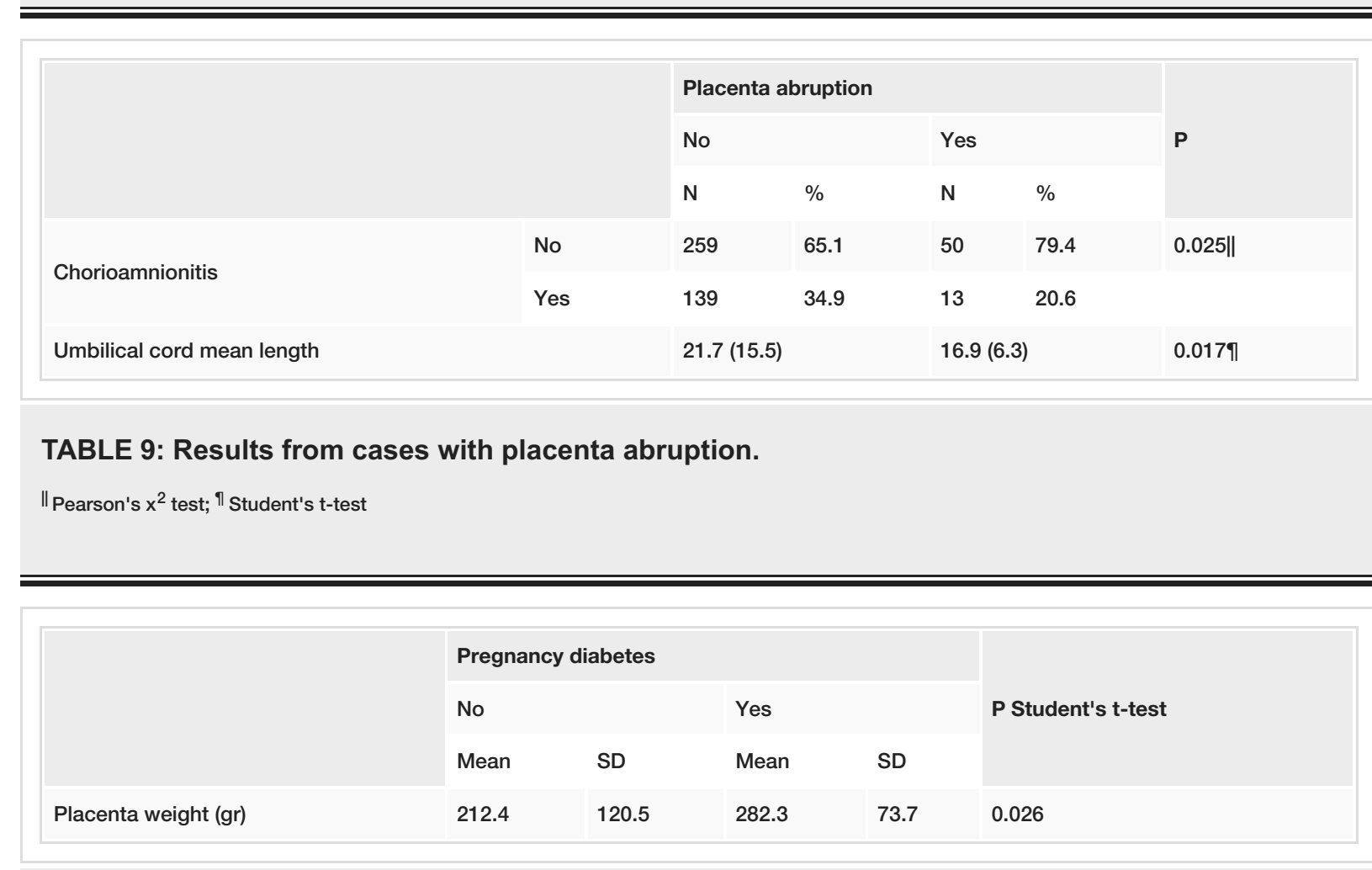

TABLE 10: Results from pregnancy diabetes.

Furthermore, Table 11 shows that deposition of fibrin was significantly associated with the presence of occlusion-intervillous hematomas-thrombi $(100 \%$ vs. $0.7 \%, \mathrm{p}<0.001)$ and vascular dysfunctions $(100 \%$ vs. $30.5 \%, \mathrm{p}<0.001)$.

\begin{tabular}{|c|c|c|c|c|c|c|}
\hline & & \multicolumn{4}{|c|}{ Fibrin deposition } & \multirow{3}{*}{ P Pearson's $x^{2}$ test } \\
\hline & & \multicolumn{2}{|l|}{ No } & \multicolumn{2}{|c|}{ Yes } & \\
\hline & & $\mathrm{N}$ & $\%$ & $\mathrm{~N}$ & $\%$ & \\
\hline \multirow{2}{*}{ Occlusion-intravillus haematomas-thrombi } & no & 404 & 99.3 & 0 & 0.0 & $<0.001$ \\
\hline & yes & 3 & 0.7 & 54 & 100.0 & \\
\hline \multirow{2}{*}{ Vascular dysfunctions } & no & 283 & 69.5 & 0 & 0.0 & $<0.001$ \\
\hline & yes & 124 & 30.5 & 54 & 100.0 & \\
\hline
\end{tabular}

TABLE 11: Results from fibrin deposition. 


\section{Cureus}

The embryonic death rate decreased by $49.7 \%$, from 32.8 per 1000 births in the years $1998-2002$ to 16.5 per 1000 births in the years 2008-2012 as it can be seen in Figure 2.

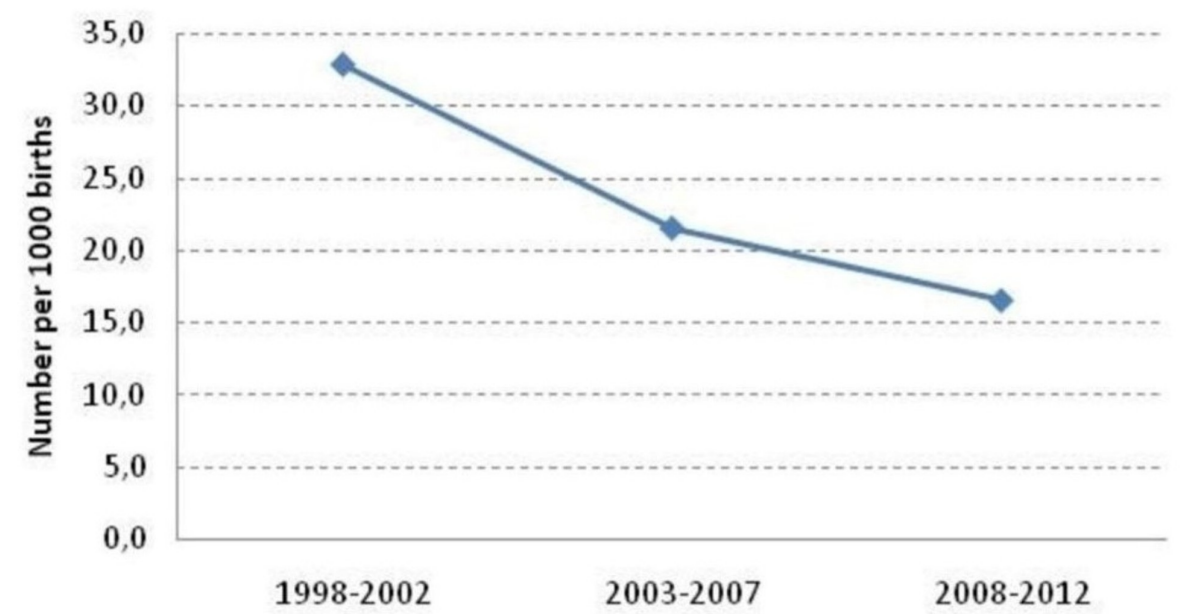

Embryonic deaths

FIGURE 2: Embryonic death rates for the three time periods.

The relative risk of embryonic death in 2003-2007 was 0.66 (95\% CI: 0.53-0.82) and significantly lower comparing births during 1998-2002, as it can be seen in Table 12. Also, the relative risk of embryonic death in 2008-2012 was 0.59 (95\% CI: 0.48-0.74) and significantly lower comparing births during 1998-2002.

\begin{tabular}{|c|c|c|c|c|}
\hline & Embryonic deaths & Births & & \\
\hline Year & N (\%) & N (\%) & Embryonic deaths (\%) & $\operatorname{RR}(95 \% \mathrm{Cl})^{*}$ \\
\hline 1998-2002 & $179(38.8)$ & $5453(28.3)$ & 32.8 & $1.00^{\ddagger}$ \\
\hline 2003-2007 & $134(29.1)$ & 6227 (32.3) & 21.5 & $0.66(0.53-0.82)$ \\
\hline 2008-2012 & $148(32.1)$ & 7603 (39.4) & 16.5 & $0.59(0.48-0.74)$ \\
\hline Total & 461 (100.0) & $19283(100.0)$ & 23.9 & - \\
\hline
\end{tabular}

TABLE 12: Relative risks (RR) with $95 \% \mathrm{Cl}$ of embryonic death according to time period of delivery.

${ }^{\star}$ Relative Risk (95\% Confidence Interval); ` Indicates reference category

\section{Discussion}

There are intensified demands on medical, political and epidemiological grounds for proper determination and

classification of cause of antepartum deaths [19, 20]. Findings from this study confirm the necessity [16] of the

microscopic examination of the placenta and umbilical cord for the purpose of parents counseling and prevention and for the comparison of health care nationally and internationally. Our findings agree with other published reports $[16,21,22]$ that the majority of stillbirths occurred in the second trimester. This illustrates the vital role of the placenta [23] and umbilical cord for the optimal fetal development [23-25]. The slight predominance of stillbirths concerned male embryo and the mean maternal age was 31.7 years. Previous studies have shown that chromosomal abnormality rate was significantly higher in male miscarriages [26]. So, these results raise multiple questions for future research whether those chromosomal abnormalities could be related with the placenta or umbilical dysfunctions. The major frequent histologic abnormalities were those indicated by placental vascular insufficiency in accordance with previous studies 
$[8,10,16]$. The second significant placenta dysfunction was found in the inflammatory disorders. Other abnormalities such as large infractions, functional-structural disorders, and placenta abruption were also studied. They were not approved of sufficient significance to this study. In addition, we noticed that the majority of multiple pregnancies which had at least one stillbirth had a monocular placenta as it can be seen in Figure 1. The umbilical cord has been examined [27] and studied in placenta autopsies. In our study, we found that inflammatory disorder was the most common umbilical cord dysfunction in antepartum deaths. The vascular disorders were present only at 6.3\%. Meanwhile, the eccentric adhesion of umbilical cord was found in most cases. This is rather due to the fact that the low and hymenus adhesion is rare than to the fact that the eccentric adhesion itself is importantly related to fetal deaths. In opposite to placenta cause, the wrapping of the umbilical cord was more frequent in the third-trimester $(\mathrm{p}<0.001)$ which was expected since the length of the umbilical cord is increased in the third trimester [28]. We noticed that only $5.4 \%$ of the cases had a single umbilical artery as it can be seen in Table 4. Therefore, we suggest that neither the adhesion of umbilical cord nor the single umbilical artery had any special role in antepartum deaths. In agreement with other studies, we proved that the rates of gestational diabetes were significantly higher in cases with single umbilical artery $(\mathrm{p}<0.001)$ as well as the congenital anomalies $(\mathrm{p}<0.001)$ [29]. Finally, our results corroborate studies showing steady declines in antepartum deaths [30] but contrast with some studies that have shown stagnating or increasing stillbirth rates. The stillbirth declined at all gestational age which reflects changes in screening policies. Nowadays we have a better postnatal management of certain anomalies such as congenital heart defects. Early termination for lethal anomalies is also permitted and is not included in stillbirths. Therefore, there is a significant decline in stillbirths at all gestational age.

\section{Conclusions}

The ability to predict and prevent stillbirth remains poor, as most stillbirths occur in women who are deemed to be at "low risk" of pregnancy complications. To reduce the fetal death rate, we need to gain more insight into the placenta causes and umbilical cord dysfunctions. This will give us the opportunity to reduce the morbidity and mortality in the setting of the placenta and umbilical cord. Obstetrical specialists should continue to carry a high index of suspicion in patients, especially in the second trimester. They have to insist on the autopsy of the placenta and umbilical cord as it remains the gold standard method in understanding the cause of an antepartum death. Through this procedure, they will gain the appropriate information for the best counseling of the parents and for planning any future childbearing.

\section{Additional Information \\ Disclosures}

Human subjects: Consent was obtained by all participants in this study. Research Committee, University of Athens issued approval B-18/ 19-12-2013. Placenta and Umbilical Cord Cause in Antepartum Deaths. The Research Committee has approved your request under condition: You will not be paid and you will be according to the law of civil liability. Animal subjects: All authors have confirmed that this study did not involve animal subjects or tissue. Conflicts of interest: In compliance with the ICMJE uniform disclosure form, all authors declare the following: Payment/services info: All authors have declared that no financial support was received from any organization for the submitted work. Financial relationships: All authors have declared that they have no financial relationships at present or within the previous three years with any organizations that might have an interest in the submitted work. Other relationships: All authors have declared that there are no other relationships or activities that could appear to have influenced the submitted work.

\section{References}

1. Khong TY, Gordijn SJ: Quality of placental pathology reports. Pediatr Dev Pathol. 2003, 6:54-58. 10.1007/s10024-001-0263-3

2. Burnley H, Moore I: An audit to assess the quality of necropsies performed on stillborn infants . J Clin Pathol. 2005, 58:93-94. 10.1136/jcp.2004.020636

3. Warland J, O'Brien LM, Heazell AE, Mitchell EA: An international internet survey of the experiences of 1,714 mothers with a late stillbirth: the STARS cohort study. BMC Pregnancy Childbirth. 2015, 15:172. 10.1186/s12884-015-0602-4

4. World Health Organization: Neonatal and Perinatal Mortality: Country, Regional, and Global Estimates . World Health Organization, Geneva; 2006.

5. Sarfraz AA, Samuelsen SO, Eskild A: Changes in fetal death during 40 years-different trends for different gestational ages: a population-based study in Norway. BJOG. 2011, 118:488-494. 10.1111/j.14710528.2010.02819.x

6. Korteweg FJ, Gordijn SJ, Timmer A, Holm JP, Ravisé JM, Erwich J: A placental cause of intra-uterine fetal death depends on the perinatal mortality classification system used. Placenta. 2008, 29:71-80. 10.1016/j.placenta.2007.07.003

7. Smith GC, Fretts RC: Stillbirth. Lancet. 2007, 370:1715-1725. 10.1016/S0140-6736(07)61723-1

8. Rayburn W, Sander C, Compton A: Histologic examination of the placenta in the growth-retarded fetus . Am J Perinatol. 1989, 6:58-61. 10.1055/s-2007-999546

9. Korteweg FJ, Gordijn SJ, Timmer A, et al.: The Tulip classification of perinatal mortality: introduction and multidisciplinary inter-rater agreement. BJOG. 2006, 113:393-401. 10.1111/j.1471-0528.2006.00881.x

10. Kalousek DK, Vekemans M: Confined placental mosaicism and genomic imprinting. Best Pract Res Clin Obstet Gynecol. 2000, 14:723-730. 10.1053/beog.2000.0107 
11. Coelho TM, Sass N, Camano L, et al.: Microvessel density in the placental bed among preeclampsia patients . Sao Paulo Med J. 2006, 124:96-100. 10.1590/S1516-31802006000200009

12. Menendez C, Castillo P, Martínez MJ, et al.: Validity of a minimally invasive autopsy for cause of death determination in stillborn babies and neonates in Mozambique: an observational study. PLoS Med. 2017, 14:e1002318. 10.1371/journal.pmed.1002318

13. Gardosi J, Kady SM, McGeown P, Francis A, Tonks A: Classification of stillbirth by relevant condition at death (ReCoDe): population based cohort study. BMJ. 2005, 331:1113. 10.1136/bmj.38629.587639.7C

14. Redman CW, Sargent IL: Latest advances in understanding preeclampsia. Science. 2005, 308:1592-1594. 10.1126/science. 1111726

15. Burton JL, Underwood J: Clinical, educational, and epidemiological value of autopsy . Lancet. 2007, 369:1471-1480. 10.1016/S0140-6736(07)60376-6

16. Nazaretian SP, Simpson I: The importance of placental examination in all fetal biopsy and postmortem examinations. J Clin Pathol. 2007, 60:846-848. 10.1136/jcp.2006.041897

17. Pantou K, Drougia A, Krallis N, Hotoura E, Papassava M, Andronikou S: Perinatal and neonatal mortality in Northwest Greece (1996-2004). J Matern Fetal Neonatal Med. 2010, 23:1237-1243. $10.3109 / 14767050903544769$

18. Tsikouras P, von Tempelhoff GF, Rath W: Epidemiology, risk factors and risk stratification of venous thromboembolism in pregnancy and the puerperium (Article in German). Z Geburtshilfe Neonatol. 2017, 221:161-174. 10.1055/s-0043-107618

19. Buitendijk S, Zeitlin J, Cuttini M, Langhoff-Roos J, Bottu J: Indicators of fetal and infant health outcomes. EJOG. 2003, 111:S66-S77. 10.1016/j.ejogrb.2003.09.007

20. Aminu M, Bar-Zeev S, van den Broek N: Cause of and factors associated with stillbirth: a systematic review of classification systems. Acta Obstet Gynecol Scand. 2017, 96:519-528. 10.1111/aogs.13126

21. Ronen JA, Castaneda K, Sadre SY: Early accreta and uterine rupture in the second trimester . Cureus. 2018, 10:2904. 10.7759/cureus.2904

22. Freedman AA, Hogue CJ, Marsit CJ, et al.: Associations between the features of gross placental morphology and birthweight. Pediatr Dev Pathol. 2018, 10.1177/1093526618789310

23. Fan D, Wu S, Liu L, Xia Q, Wang W, Guo X, Liu Z: Prevalence of antepartum hemorrhage in women with placenta previa: a systematic review and meta-analysis. Sci Rep. 2017, 7:40320. 10.1038/srep40320

24. Hirst JE, Villar J, Victora CG, et al.: The antepartum stillbirth syndrome: risk factors and pregnancy conditions identified from the INTERGROWTH-21st Project. BJOG. 2018, 125:1145-1153. 10.1111/14710528.14463

25. Senkoro E, Mwanamsangu AH, Chuwa FS, Msuya SE, Mnali OP, Brown BG, Mahande MJ: Frequency, risk factors, and adverse fetomaternal outcomes of placenta previa in Northern Tanzania. J Pregnancy. 2017, 2017:7. 10.1155/2017/5936309

26. Ouyang Y, Tan Y, Yi Y, Gong F, Lin G, Li X, Lu G: Correlation between chromosomal distribution and embryonic findings on ultrasound in early pregnancy loss after IVF-embryo transfer. Hum Reprod. 2016, 31:2212-2218. 10.1093/humrep/dew201

27. Olaya CM, Michael F, Fabian G, Silva JL, Bernal JE: Role of VEGF in the differential growth between the fetal and placental ends of the umbilical cord. J Neonatal Perinatal Med. 2018, 22:1-17. 10.3233/NPM-1795

28. Georgiadis L, Keski-Nisula L, Harju M, Räisänen S, Georgiadis S, Hannila M-L, Heinonen S: Umbilical cord length in singleton gestations: a Finnish population-based retrospective register study. Placenta. 2014, 35:275-280. 10.1016/j.placenta.2014.02.001

29. Xu Y, Ren L, Zhai S, et al.: Association between isolated single umbilical artery and perinatal outcomes: a meta-analysis. Med Sci Monit. 2016, 22:1451-1459. 10.12659/MSM.897324

30. Zeitlin J, Mortensen L, Cuttini M, et al.: Declines in stillbirth and neonatal mortality rates in Europe between 2004 and 2010: results from the Euro-Peristat project. J Epidemiol Community Health. 2016, 70:609-615. 10.1136/jech-2015-207013 